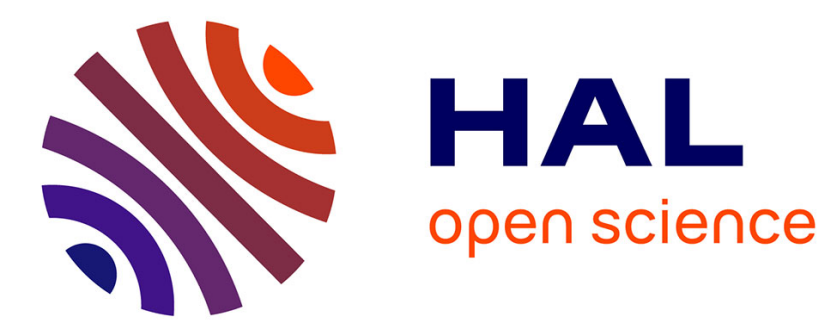

\title{
An onion-like movement corridor? Possible guidelines emerging from small-scale movement rules.
}

Thomas Delattre, Jacques Baudry, Françoise Burel

\section{To cite this version:}

Thomas Delattre, Jacques Baudry, Françoise Burel. An onion-like movement corridor? Possible guidelines emerging from small-scale movement rules.. Ecological Informatics, 2018, 45, pp.48-58. 10.1016/j.ecoinf.2018.03.006 . hal-01828553v2

\section{HAL Id: hal-01828553}

\section{https://hal-univ-rennes1.archives-ouvertes.fr/hal-01828553v2}

Submitted on 14 Sep 2018

HAL is a multi-disciplinary open access archive for the deposit and dissemination of scientific research documents, whether they are published or not. The documents may come from teaching and research institutions in France or abroad, or from public or private research centers.
L'archive ouverte pluridisciplinaire HAL, est destinée au dépôt et à la diffusion de documents scientifiques de niveau recherche, publiés ou non, émanant des établissements d'enseignement et de recherche français ou étrangers, des laboratoires publics ou privés. 
An onion-like movement corridor? Possible guidelines emerging from small-scale movement rules.

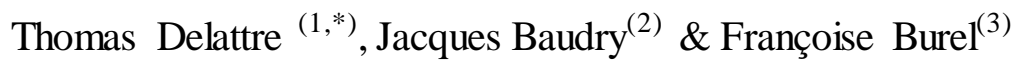

1 French National Institute of Agronomic Research (INRA), UR1115 PSH, Avignon, France

2 French National Institute of Agronomic Research (INRA), UR0980 SAD Paysage, Rennes, France

3 French National Center for Scientific Research (CNRS), UMR6553 ECOBIO, Rennes, France

* corresponding author: thomas.delattre@ inra.fr

Date of the manuscript draft: 02/07/2017

Manuscript word count: 7769 


\begin{abstract}
:
Ecological corridors are among the most used items in the conservationist's toolbox. However, their efficiency is regularly questioned, highlighting possible discrepancies between ecological processes and conservation goals. While frequently advocated for its benefits for biodiversity as a whole, corridors are generally designed according to a binary representation of landscape that brings mixed benefits.

We focused on movement corridors designed for "passage species", i.e. using a corridor throughout a single lifecycle. Because their functional requirements are different from those of corridor dwellers, we expected that the relationship between ground cover and connectivity may deviate from the common habitat-matrix paradigm.

We concentrated on individual movement rules at the core of the corridor functioning, by implementing basic mechanisms from dispersal ecology in an individual-based model. We evaluated the connectivity benefits brought by unconventional corridor designs.

Our simulations suggested that movement corridors with an unfavourable ground cover could be more efficient than those with a favourable ground cover. An "onion corridor" composed by several overlaid layers of habitats could help decrease the frequent leaks of dispersers from the core of the corridor. In mosaic corridors composed by several patches of habitats, both compositional and structural heterogeneity decreased connectivity. However, a mosaic of habitats used as a buffer around an onion corridor increased its connectivity. Such designs could be useful in agricultural landscapes, by increasing connectivity while having a low impact on farming practices.
\end{abstract}

Keywords: movement corridors, dispersal, individual-based modelling, context-dependent movement 


\section{Introduction:}

Habitat fragmentation is one of the major causes of the current massive species extinctions observed in human-altered ecosystems (Saunders et al. 1991; Vitousek et al. 1997; Lawler et al. 2006; Pereira et al. 2010). While the fragmentation sensu stricto may occasion positive effects in specific situations, they are generally dominated by its detrimental effects acting by way of both habitat loss and habitat isolation (Tscharntke et al. 2002; Fahrig 2003). Habitat loss directly affects the metapopulation size of a given landscape, increasing the vulnerability of local populations to environmental, genetic and demographic stochasticity (Soulé and Gilpin 1991; Ceballos and Ehrlich 2002; Fahrig 2003). Habitat isolation also increases the probability of extinction of local populations (Hanski 1999; Brook et al. 2002; Rodriguez and Delibes 2003). At the same time, it reduces the probability of successful immigration, which decreases the rescue effect (Brown and Kodric-Brown 1977) and the frequency of (re)colonisation of empty habitats (Hanski 1998; Hanski 1999).

In this context, the major way to limit populations and species extinctions would be to increase the habitat area and at least limit its erosion (Hodgson et al. 2011). That solution is, however, increasingly challenging in the context of the logarithmic growth of the human population and heavily human-dominated landscapes. Moreover, the social acceptance of a reallocation of portions of the landscape for conservation purposes is frequently difficult to obtain, as seen with agri-environmental schemes (Burton et al. 2008).

Those constraints may explain the appeal of the linkage strategy, a complementary approach that aims at restoring the functionality of the ecological network by facilitating the movement of individuals among populations with corridors or stepping stones (Beier and Noss 1998; Bennett 1999; Jongman and Pungetti 2004; Chetkiewicz et al. 2006a; Baguette and Van Dyck 2007; Baguette et al. 2013) in order to increase the viability of existing habitats. Indeed, the metapopulation theory (Hanski 1999) and a solid set of empirical evidences e.g. (Beier and Noss 1998; Griffen and Drake 2008; Stevens and Baguette 2008; Gilbert-Norton et al. 2010; Doerr et al. 2011) support the main prerequisite of the linkage strategy, namely that increasing the frequency of movement of individuals between populations enhance the persistence of metapopulations. Accordingly, ecological corridors have been one of the most used items in the conservationist's toolbox during the last decades, even attaining continental scale endorsement (e.g. Boitani et al. 2007). However, the efficiency of the ecological corridors has been regularly questioned (Simberloff et al. 1992; Hodgson et al. 2011) highlighting a possible discrepancy between ecological process and conservation goals.

Ecological corridors may actually be separated in two distinct categories with different conservation goals 
and different underlying processes, that should be studied separately (Beier et al. 2008). The movement corridors are designed for passage species, i.e. species that can use a corridor to move between habitat patches in less than a single individual lifecycle. On the contrary, habitat corridors are designed for corridor dwellers, i.e., species that require more than one generation to move between habitat patches. Movement corridors and habitat corridors rely on different ecological processes and require different conservation measures (Beier et al. 2008). Corridor dwellers must successfully establish and reproduce within the corridor to cover the corridor length over several generations, which means that corridor quality should ideally be as high as or greater than the quality of larger patches (Tilman et al. 1997). This category of corridors applies well to many cases of regional-scale corridors, frequently targeted at large mammals (e.g. Kramer-Schadt et al. 2011; Theobald et al. 2012; Kanagaraj et al. 2013; Belote et al. 2016) - and those species and situations may not benefit from this study. On the contrary, passage species may use corridors for movement only, which relaxes the need for resources to host a population, and brings the focus on how the small-scale, behavioural mechanisms allow the corridor to influence the species dispersal at larger scales (Dover et al. 1997; Haddad 1999a; Dover and Fry 2001; Chetkiewicz et al. 2006b). In this study, we chose to focus on movement corridors designed for passage species, and accordingly, we opted to ignore habitat corridors designed for corridor dwellers. Because movement may occur in both favourable and hostile habitats, and because movement strategies are strongly affected by the characteristics of the ground cover (Van Dyck and Baguette 2005) the composition and structure of effective movement corridors may cover a wider range of ground cover quality.

We used an Individual-Based Model (Grimm 1999; Grimm and Railsback 2013) simulating movements of animals in a simplified landscape composed of two habitat patches connected by a variety of corridor setups and matrix characteristics. IBMs allow representing the structures of the landscape and their effects on movement behaviour of individuals, a crucial requirement for connectivity estimators to be reliable and generalisable to other species based on their dispersal traits (Taylor et al. 1993; Baguette et al. 2013). Simple IBM approaches like the Stochastic Movement Simulator (Coulon et al. 2015) have proven to be significantly more efficient in predicting connectivity than least-cost paths or circuit theory, by relaxing the assumption of individual omniscience, relying on realistic movement rules and allowing to account for several possible pathways among patches. Interestingly, the latter allows evaluating scenarios where connectivity is achieved through both optimal and suboptimal pathways, i.e. corridors only, matrix only or a combination of both (Drift Fence Hypothesis, (Haddad and Baum 1999)). Moreover, IBM based on dispersal ecology allow relaxing the common assumption that animals choose travel routes on the basis of the same factors they use 
to choose habitat (Chetkiewicz et al. 2006b) which may not always be true (Beier et al. 2008; Oliver et al. 2009). Like the SMS model (Coulon et al. 2015) this was done here at the cost of only two additional parameters. Those two classics of dispersal ecology (Baguette and Van Dyck 2007) are observed in a very wide range of organisms: directional persistence and the reluctance to cross a boundary. Reluctance to cross a boundary is a behaviour playing an essential role in both the first and last steps of dispersal (emigration and immigration (Baguette and Van Dyck 2007)). It is influenced by the contrast between the sides of the boundary (Holmquist 1998; Collinge and Palmer 2002; Haynes and Cronin 2006; Gillies and St. Clair 2008; Prevedello and Vieira 2010; Delattre et al. 2013). Directional persistence, i.e. the tendency to follow a correlated path (Zollner and Lima 1999) is one of the most frequently used markers of net movement efficiency during the second step of dispersal (Baguette and Van Dyck 2007). Individuals moving in suitable habitats use sinuous paths adapted to foraging (i.e. low directional persistence), while individuals moving in hostile matrix use straighter paths adapted to dispersal (i.e. high directional persistence) (Schultz 1998; Goodwin and Fahrig 2002; Baguette 2003; Van Dyck and Baguette 2005; Schtickzelle et al. 2007b).

Using that IBM, we explored the potential benefits of ecological corridors composed of a wide range of ground covers and surrounded by a wide range of matrix quality, including combinations that differ strongly from the generic good corridor-bad matrix design. We evaluated the effects of two spatial structures complementing the generic, one-linear-patch-type corridor design. First, an onion-like, multi-strips corridor consisting of two linear landscape elements arranged as buffers along a core area (Fig. 1C). Second, a mosaic corridor composed by a diversity of ground covers arranged as a linear mosaic of patches (Fig. 1D). Additionally, we analysed the effects of the composition and structure of the mosaic in the vicinity of the corridors (Fig. 1A, 1B \& 1F).

\section{Methods:}

Here below we propose a summarised description of the Individual-Based Model created and used in this work, based on the ODD protocol ("Overview, Design concepts, Details”) (Grimm et al. 2006; Grimm et al. 2010). The model was created with NetLogo (Tisue and Wilensky 2004) and analysed in $R$ (R Development Core Team 2009). The model supporting the conclusions of this article is available in the GitHub repository (https://github.com/tdelattre/m2c). The results presented in Figures 2 to 7 may be used as a sensitivity analysis, because the two behavioral parameters of the model vary in a strictly proportional relationship with habitat quality. 


\section{Model overview}

The purpose of this model is to improve our understanding of how corridors composed of several ground covers interact with dispersal traits to fulfil dispersal efficiency. We apply this general question to the interaction between habitat quality and behavioural parameters associated with the first two of the three different phases of dispersal (emigration and transfer).

We chose to work with virtual species to improve the generality of our conclusions. There is neither reproduction nor resource consumption, and the model runs until all individuals move over a given distance. Because the model is not species-specific, the grid cells do not represent real units of space: their variations should only be considered relatively to movement ability. This way, we are allowed to consider a great variety of ratios between species movement ability and corridor dimensions.

\section{The landscape}

The model simulates a landscape in which individuals move freely. The landscape is composed of two round habitat patches (170 pixels $\left.{ }^{2}\right)$, connected by a corridor and surrounded by a matrix. The landscape is an $800 \times 800$ grid of cells, each of which is characterised by its habitat quality ranging from 0 to 100 (relative values, respectively from hostile to perfectly suitable). While the quality of the habitat patches is always good, both the corridor and the matrix may be composed of a wide range of ground covers qualities (i.e., a series of ground qualities that will be perceived as hostile to favourable by moving individuals). In some scenarios, the core of the corridor may be surrounded by a "buffer": a pair of strips separating it from the surrounding matrix. The structure of the corridor, the buffer and the matrix are either uniform or composed by a mosaic of patch types distributed as Voronoi polygons (Aurenhammer 1991). The density of the Voronoi polygons may vary from 0 to 40 seeds, which corresponds to patch areas ranging from 725 pix $^{2}$ to 115 pix $^{2}$. The density of polygons is used as a proxy for structural heterogeneity. The quality of the Voronoi polygons may be identical, or vary following a standard deviation around the mean habitat quality (from $s d=1$ to $s d=8$ ), which is used as a proxy for compositional heterogeneity. The configuration of the corridor (width, the number of strips, structural homogeneity, and composition) and that of the matrix (structural homogeneity, composition) may vary. The length of the corridor (the inter-patch distance) is fixed to avoid confounding effects. The corridor is 500 pixels long, which given the dispersal ability of the agents (see below, movement sub-model), allows isolating the patch when the ground cover does not favour movement while remaining in the range of attainable distances when ground cover improves (e.g., Figure 2).

\section{The agents}


The model is initiated with identical parameter values for all individuals. Basic state variables include their identity number, their position (grid cell coordinates), and their "flight range" (the distance over which they can move). Virtual individuals can detect the ground cover of the cell in which they are and behave accordingly, but they cannot detect each other or get direct information about the population density in their patch. At each time step, each individual moves to the next pixel according to cover-dependent rules (see below, movement sub-model).

\section{Initialisation, simulation plan and data extraction}

Each simulation begins with an initial seed of 4000 individuals, placed on the centres of habitat patches, and facing a random direction.

Series of landscape scenarios were evaluated according to their effect on functional connectivity as follows (cf. Figure 1 for graphic examples):

- $\quad$ Generic corridor structure:

- effect of a variation of the habitat quality of the corridor (uniform corridor surrounded by a uniform matrix, no buffer) ranging from 0 to 100.

- habitat quality of the matrix (uniform corridor surrounded by a uniform matrix, no buffer) ranging from 0 to 100

- Onion corridor:

- habitat quality of the buffer (uniform corridor surrounded by a uniform buffer, and a uniform matrix) ranging from 0 to 100 .

- Mosaic corridor:

- compositional and structural heterogeneity of the corridor (surrounded by a uniform matrix, no buffer) ranging from $s d=1$ to $s d=8$ (composition) and 0 to 40 seeds (structure).

- Mosaic matrix and buffer

- compositional and structural heterogeneity of the matrix (uniform corridor, no buffer) ranging from $s d=1$ to $s d=8$ (composition) and 0 to 40 seeds (structure).

- compositional and structural heterogeneity of the buffer (uniform corridor, uniform matrix) ranging from $s d=1$ to $s d=8$ (composition) and 0 to 40 seeds (structure). 
In each and every landscape design, the habitat patches were composed of good habitat quality. We ran 1000 repetitions of each of the landscape designs to take into account the inherent stochasticity of the model design.

We separated individuals that succeeded after going through the matrix only (hereafter, "pure matrix movements"), through the corridor only (hereafter, "pure corridor movements") and through a combination of matrix and corridor corresponding to the Drift Fence Hypothesis (hereafter, "DFH movements").

\#Figure 1 approximatelyhere\#

\section{Movement model}

The basic design of the model considers dispersal as a context-dependent ecological process (Clobert et al. 2009), in which the landscape attributes and individual behaviours interact to generate the final dispersal pattern. Dispersal is usually divided into three phases (emigration, transfer, immigration) (Baguette and Van Dyck 2007; Clobert et al. 2009), the first two of which are addressed separately in the model with two parameters (respectively, the probability to cross a boundary and directional persistence).

Individuals are allowed to move 10,000 times. At each time step, each individual will move to one of its neighbour cells (Moore neighbours). The next cell (i.e. the step direction) is either the cell that the individual is currently facing (straight step), or chosen randomly (turning step) with a probability to change direction that is inversely proportional to the suitability of the current pixel $(0-100 \%)$. This function reproduces Directional Persistence, i.e. the tendency to follow a correlated path (Lima and Zollner 1996). Individuals foraging in suitable ground covers use sinuous paths (i.e. low directional persistence), while individuals dispersing in unsuitable areas use straighter paths (i.e. high directional persistence ) (Baars 1979; Schultz 1998; Goodwin and Fahrig 2002; Baguette 2003; Van Dyck and Baguette 2005; Schtickzelle et al. 2007a). In our model, the sinuosity is approximated by the frequency of turns, and ranges from $100 \%$ (fully random movement) to $0 \%$ (straight line).

Simulated individuals hitting a boundary between two different ground covers may cross it with a probability that is proportional to the suitability of the target pixel $(0-100 \%)$. This function reproduces the reluctance to cross a boundary (Baguette and Van Dyck 2007) which is influenced by the contrast between the sides of 
the boundary (Holmquist 1998; Collinge and Palmer 2002; Haynes and Cronin 2006; Gillies and St. Clair 2008; Prevedello and Vieira 2010; Delattre et al. 2013).

When an individual moves between two pixels, the probability that it changes direction is inversely proportional to the suitability of the ground cover of the pixel of origin. This function reproduces Directional Persistence, i.e. the tendency to follow a correlated path (Lima and Zollner 1996). Individuals foraging in suitable ground covers use sinuous paths (i.e. low directional persistence), while individuals dispersing in unsuitable areas use straighter paths (i.e. high directional persistence) (Baars 1979; Schultz 1998; Goodwin and Fahrig 2002; Baguette 2003; Van Dyck and Baguette 2005; Schtickzelle et al. 2007a).

An individual that reaches the target habitat patch stops moving, is deleted and is recorded as a success. Functional connectivity is measured as the proportion of individuals successfully reaching the target habitat.

\section{Results:}

\section{Testing a broad range of habitat qualities and boundary contrasts in the classical corridor design}

Over the range of simulated corridor configurations, the majority of the connectivity benefits was the result of pure corridor movements, and to a lesser extent of DFH movements (Figures 3, 7). Comparatively, pure matrix movements were negligible.

We observed that the highest connectivity (\% of individuals having moved from $A$ to $B$ ) was obtained when both the matrix and the corridor quality were at their lowest, but the corridor quality was slightly better than that of the matrix (Fig. 2 A). In that configuration, connectivity was primarily the result of pure corridor movements (Fig. $2 \mathrm{~A}$ and $2 \mathrm{~B}$ )

\#Figure 2 approximatelyhere\#

Typical situations when the corridor quality was bad (10-20) and the surrounding matrix was suitable (over a wide range of quality values, 15-95) showed good functional connectivity. Successful movements were in the 
majority DFH movements (Fig. 2 B). More generally, DFH movements were more frequently observed with higher matrix quality.

\section{The effect of additional contrasted habitat strips on movement corridors}

\section{\#Figure 3 approximatelyhere\#}

The addition of a buffer along the core of the corridor had contrasted effects when the core of the corridor was of bad versus good quality. When the quality of the corridor was bad, the baseline connectivity was already very high, so the addition of a buffer brought little benefit (Figure 3, Core $=10$ ). Moreover, the addition of a contrasted buffer proved less useful than adding a buffer of the same quality as the core of the corridor (i.e. increasing the width of the corridor). Adding a buffer of better quality than the core even decreased connectivity, compared to no addition at all (Fig. $3 \mathrm{~A}, \mathrm{~B}$ ). When the quality of the corridor was intermediate or good, the baseline connectivity was relatively low. Adding a buffer of bad quality increased notably the connectivity by increasing pure corridor movements. However, a buffer of good quality decreased connectivity.

Overall, we observed that the buffer was not necessary to obtain a good connectivity (Fig. 3). However, in simulations of good quality corridors without a buffer, $86 \%$ of the connectivity was due to DFH movements (Fig. $3 \mathrm{~A}, \mathrm{C}$ ), i.e. individuals that emigrated from the corridor into the matrix at least once during their movement. In particular, we observed that in the well-known configurations close to the classical corridor design (core $=90$ ). In every configuration, adding a buffer helped to reduce DFH movements (Fig. 3 C).

\section{The effect of a mosaic of patches with contrasted ground covers}

\section{The efficiency of corridors composed of a mosaic of patches}

When the mean quality of the corridor was bad, a heterogeneous corridor consisting of a mosaic of patches was twice less efficient than a homogeneous corridor. When the mean quality of the corridor was good, a mosaic corridor was as favourable as a homogeneous one (Fig. 7 B and 4).

Both structural heterogeneity (here, the density of patches) and the compositional heterogeneity (here, the 
variation in ground cover quality) had an adverse effect on connectivity (Fig 4). The homogeneity of the surrounding matrix did not change this effect (not shown here).

\#Figure 4 approximatelyhere\#

\section{The effect of the habitat mosaic surrounding the corridor}

Both compositional and structural heterogeneity of the matrix mosaic increased functional connectivity (Fig.

5). Connectivity gains were uniquely due to increases in the efficiency DFH movements, while pure corridors and pure matrix movements were not affected (not show here).

\#Figure 5 approximatelyhere\#

\section{The effect of a buffer composed of a mosaic of patches}

A corridor buffer consisting of a mosaic of patches did not improve connectivity over a buffer composed of a homogeneous ground cover (Figure 6 and Figure 7). Both structural and compositional heterogeneity in the buffer decreased connectivity (Figure 6). Both DFH movements and pure corridor movements showed a slight decline, while pure matrix movements were unaffected (Figure 7).

\#Figure 6 approximatelyhere\#

General comparison of the classic, mosaic and onion corridor designs 
\#Figure 7 approximatelyhere\#

When the quality of the core of the corridor was bad, there was little benefit in complicating its structure (Figure 7 A). The most efficient corridor was the simple corridor composed of only one type of unsuitable ground cover. An onion corridor and a mosaic buffer brought similar connectivity, with small decreases in DFH movements and pure matrix movements signalling a reduction in emigration from the corridor. The least efficient of all the configurations was a corridor entirely composed of a mosaic of patches, which caused a notable decrease in successful pure corridor movements. Aside from the differences between each configuration, every corridor brought connectivity benefits orders of magnitudes higher than that of the matrix alone.

When the core of the corridor was of good quality, there were significant benefits in complicating its structure (Figure $7 \mathrm{~B}$ ). A simple corridor composed of only one type of good ground cover was the least efficient form. The essential part of the connectivity brought by the simple corridor was the result of DFH movements, while connectivity due to pure corridor movements was very low. An onion corridor was the form of corridor that brought the best increases in connectivity. Pure corridor and DFH movements were higher than those of other configurations and contributed equally to connectivity in this form. A corridor with a buffer composed of a mosaic of patches was the second-best configuration. Pure corridor and DFH movements contributed equally to connectivity in this corridor form. A mosaic corridor did not affect connectivity compared to a simple corridor. 


\section{Discussion:}

The interactions between contrasts in ground cover quality and simple rules from dispersal ecology, and their consequences on the corridor function

In this study, we explored the efficiency of ecological corridors with a focus on passage species (Beier et al. 2008). Since the targeted corridor was a movement corridor, its main objective was to promote individual movements, while the requirement for high-quality habitats to sustain population viability inside corridors was relaxed. That assumption allowed for an interesting variety of predictions, because it expanded the range of possible ground covers, and because predictions of the corridor efficiency ultimately rely on fine-scale interactions between dispersal rules and ground cover quality (Dover et al. 1997; Haddad 1999b; Dover and Fry 2001; Chetkiewicz et al. 2006a).

Although some of our predictions based on dispersal rules were counterintuitive, our results supported the common assumption of the efficiency of corridors. Indeed, movements of individuals were facilitated by most configurations of corridors tested in this study. The majority of the connectivity benefits was the result of movements through the corridor, but also through movements through both the corridor and the matrix similar to the Drift Fence Hypothesis (Haddad and Baum 1999). Comparatively, pure matrix movements were quantitatively negligible.

\section{Managing corridors for special moves:}

Special dispersal movements have evolved in a high number of taxa (Baguette and Van Dyck 2007). These movements are observed when ground cover quality is bad and are adapted to long-distance dispersal (LDD), i.e. movements between distant habitats in a hostile matrix. When the ground cover quality is good, individuals prefer routine, sinuous movements, which are well adapted to foraging but confer a poor dispersal efficiency (Baguette and Van Dyck 2007). As a consequence, individuals moving into a corridor composed of good quality habitat will use movements that are not well suited to dispersal (Delattre et al. 2013), which is in apparent contradiction with the corridor's primary objective of increasing connectivity. Here, we propose that movement corridors with a ground cover of bad quality, designed to promote special moves, could be more efficient than movement corridors with a ground cover of good quality, that trigger routine movements. This prediction should apply to any species in which a context-dependent selection of routine or special movements has been observed, such as beetles, butterflies, ungulates, and including both habitat-specialist and habitat-generalist species (Van Dyck and Baguette 2005). Our simulations predict a 
better functional connectivity when individuals moving through the corridor perceive its quality as bad. That proposal meets with two main difficulties. (1) First, organisms moving into landscape elements of bad quality incur direct and indirect costs (Bonte et al. 2012) that should be weighed against their connectivity benefits. However, one could manage the ground cover of corridors in such a manner that they would both be perceived as bad habitats and reduce dispersal costs. For example, stakeholders could be more demanding in their control of sources of direct costs inside the corridor (e.g. mortality sources like pesticide exposure), independently of the ground cover quality as it is perceived by the species of interest. Additionally, indirect costs like energetic costs induced by the absence of resources could be decreased by the addition of borders containing resources around the core of the corridor. Our simulations predict that such a configuration would only slightly decrease connectivity over a simple bad quality corridor (Figure 3), which may be compensated by the decrease in energetic costs. (2) Second, a corridor with bad habitat quality might offer lower contrast with the surrounding matrix, leading to higher emigration rates from the corridor that would decrease its efficiency (Tischendorf and Wissel 1997; Vos et al. 2002; Delattre et al. 2010b; Delattre et al. 2013). Our simulations suggest that the negative impact of this "strainer effect" is low compared to the benefits of more efficient movements (Figure 3). Still, adding buffers of higher quality would help maintain individuals into the corridor (Figure 3) while potentially decreasing movement costs by providing them resources. Both indirect movement costs and the strainer effect are expected to increase exponentially with the distance moved (Delattre et al. 2010b; Bonte et al. 2012) which means that conservationist should tackle these difficulties with a growing concern when the interpatch distance nears the maximum dispersal ability of the species of interest.

Although counterintuitive at first, the recommendation of bad quality corridors makes sense in the context of the ecological trap theory (Schlaepfer et al. 2002). Indeed, at least in human-dominated landscapes, ecological corridors are human-managed, artificial landscape elements. The ecological trap theory predicts that, in some situations, human-managed ecosystems differ from the situations in which organisms have evolved, luring them into maladapted behaviours that decrease population viability. However, organisms could also be lured into behaviours improving population persistence. More specifically the conservationists could create corridors of badly quality to lure individuals into movement behaviours allowing more efficient dispersal. The consequence would be to decrease the time spent by dispersing individuals into the corridor, and increasing the time spent in habitats that are actually fit to sustain a population.

In another, very specific situation, we predict that the connectivity inside a large habitat patch could be improved by a corridor cut inside the very core of the patch. Wood clearings provide good examples of 
this effect, and have been shown to be efficient corridors for a variety of taxa, e.g. (Haddad and Baum 1999). In our simulations, a corridor of bad quality surrounded by a matrix of good quality provided significant benefits in connectivity. That structure allowed individuals to perform short but very efficient "bursts" of dispersal into the corridor. Although it is rare - and probably undesirable - to observe landscapes where similar structures would be set up explicitly to improve connectivity, open spaces in forest such as clear-cuts and power line corridors may favour the connectivity of species and pathogens inside large forest patches (Viljur and Teder 2018).

In our simulations, a substantial proportion of individuals dispersing through the corridor tended to use the unsuitable ground cover of the matrix at least once in their pathway. For example, in configurations similar to the classical corridor design (i.e., the good corridor-bad matrix configuration), we observed that a majority of the successful movements used both matrix and corridor $(7 \mathrm{~B})$. It suggests that in the most frequent corridor configuration, the corridor itself may be used only partially for movement. The corridor may serve as a guide and a refuge towards which individuals regularly go back while covering the essential of the distance in the matrix. Such movements could also correspond to the predictions of the Drift Fence Hypothesis (Haddad and Baum 1999) in which individuals emigrate from a habitat patch, move in the matrix and are "captured" by the corridor, to be eventually directed into the target habitat patch. Alternatively, it is possible that those individuals moving into the corridor shortly wander in the matrix, then rapidly go back to the corridor in a "foray loop", a behaviour that is frequently observed near habitat boundaries but whose function is still discussed (Conradt and Roper 2006; Crone and Schultz 2008; Delattre et al. 2010a; Mclntire et al. 2013).

This prediction highlights the importance of managing the immediate vicinity of the corridor (Tischendorf and Wissel 1997; Vos et al. 2002). It would be of particular concern in the case of corridors with low habitat quality. Although we predict that those corridors would be very effective in favouring dispersal, their boundaries might show lower contrast with the surrounding matrix. Therefore, the number of individuals emigrating from the corridor might be more important, all the more so as corridors would be narrow and long. The frequency of emigration from the corridor should be managed cautiously in such a design, to avoid situations where the benefits of higher dispersal rates would be compensated by an important strainer effect increasing mortality rates.

The proposal of corridors for special movements differs from the corridor design that is generally advocated. However, examples of similar designs have been documented and favour connectivity. For example, 
corridors for special movements could take the form of low-quality grassy strips (intensively mowed, or with a low plant diversity) connecting natural or semi-natural grasslands for grassland specialists and generalist butterfly species (Haddad and Tewksbury 2005; Delattre et al. 2013). Forest patches could be connected by scattered hedgerows and hedgerows providing insufficient resources or vegetation cover due to unfitting tree species or intensive management practices, while still increasing connectivity for forest birds, beetles and small mammals (Burel and Baudry 1995; Gillies and St. Clair 2008).

\section{An onion-like corridor: how an additional, contrasted strip could improve the effects of corridors on movement}

The immediate surroundings of the corridor may significantly alter its efficiency (Tischendorf and Wissel 1997; Vos et al. 2002; Delattre et al. 2013). Here, we propose to integrate them explicitly in the corridor design, by buffering the core of the corridor with a pair of additional strips of contrasted ground cover. Such an "onion-like corridor" (composed by several overlaid layers) should help decrease the leaks, improve the directionality of movements, and decrease the costs associated with occasional DFH movements.

Indeed, our simulations in which the second strip was an absolute barrier provided excellent connectivity results (e.g. Fig. 2 A). However, corridors surrounded by absolute barriers might be relatively rare in real landscapes, with the notable exception of corridors in urban areas (e.g. Savard et al. 2000; Herzele and Wiedemann 2003).

However, scenarios of onion corridors where the contrast between the corridor and its buffer were lower, showed mitigated benefits. Adding a buffer of lesser or higher quality than the core corridor did not or only slightly increased connectivity over a simple corridor, and even decreased the connectivity when the core quality was good. In the only situation when a bad quality buffer brought a significant increase in connectivity over a simple corridor (when the core quality was bad, Fig 3), we observed that increasing the width of the core of the corridor by the same proportions (i.e. larger, homogeneous corridor) brought better results. Indeed, a bad quality corridor already brought excellent connectivity benefits, which were mainly provided by individuals moving through the corridor only, without emigration, and therefore unaffected by border management. Interestingly, this suggests that the linearity of their paths spare those individuals from frequently encountering the borders of the corridor, therefore decreasing the probability of emigration from the corridor. That mechanism could be an additional benefit of bad quality ground covers: by triggering special moves inside corridors, they could simultaneously reduce emigration towards the matrix and increase 
pure movement efficiency.

Apart from the pure connectivity benefits, we observed that buffered corridors changed the pathways followed by individuals between two patches. In fact, we noted that the addition of a buffer of lesser quality notably improved the proportion of successful dispersers using pure corridor movements (when the quality of the core was good or intermediate, Fig. 3). Similarly, every buffer addition to a simple corridor helped to decrease the number of individuals reaching the target patch through a DFH pathway (Fig. 3). Whether it is a benefit or a drawback from a conservation perspective will depend on the situation considered. In situations where the matrix is very hostile, preventing individuals to move outside of the corridor could help avoid the associated costs.

Existing examples of multi-strips corridors include grassy field margins bordered by dense hedgerows, where the hedgerow provides a barrier that prevents dispersers from leaking from the corridor (Delattre et al. 2013). Such configurations are observed in European landscapes along watercourses, and emerge from spatial correlations between agri-environmental schemes and cultural habits of hedgerow management (Burel and Baudry 1990; Ernoult et al. 2013). Similarly, ecological corridors implemented in urban landscapes are frequently surrounded by buildings and walls that are impermeable to movements (Savard et al. 2000).

\section{Integrating a mosaic of contrasted patches in the design of movement corridors:}

As for every conservation strategy, the setup of movement corridors needs to account for the diversity of habitats in the landscape (Fahrig et al. 2010) especially in agricultural areas (Vasseur et al. 2013). It may be especially true of movement corridors that suffer from a binary representation of the landscape (Hess and Fischer 2001; Gilbert-Norton et al. 2010) being typically set up as one specific type of suitable habitat embedded in a uniform and unsuitable matrix (Forman 1983; Beier and Noss 1998). Despite their homogeneity, movement corridors are frequently built with broad conservation objectives in mind, targeting several species or even "biodiversity" as a whole, notwithstanding the diversity of habitat requirements of different species. This is fort example the case of the European policy on ecological networks which aims at preserving "biodiversity" (Jongman and Pungetti 2004).

One solution to this problem would be to design movement corridors composed of several habitat types (e.g. Eggers et al. 2009). To evaluate the effect of such a design on movement, we integrated the fundamentally binomial corridor strategy with a mosaic of patches with contrasted ground covers. We evaluated the effect of the mosaic included inside the corridor, and that of the mosaic managed near the corridor. 


\section{A corridor composed of a mosaic of patches}

Our simulations predicted that the benefits of an addition of a mosaic of patches over a simple, one-habitat corridor depended on the mean quality of the added patches. A heterogeneous corridor consisting of a mosaic of unsuitable patches would be half as efficient as a simple, bad quality corridor. However, a corridor composed of a mosaic of good habitat patches would be as effective as a simple, good-quality corridor.

Increases in both structural and compositional heterogeneity of the corridor decreased connectivity. Certainly, the succession of boundary reflections inside the corridor scattered the pathways of the dispersers, causing frequent turns and decreasing the dispersal efficiency.

We suggest that, if the conservationist focus is on connectivity alone, integrating a mosaic of patches in the design of corridors may not be a panacea. A simple, bad quality corridor could be more efficient to reach pure connectivity goals. More specifically, creating mosaic corridors by managing the existing agricultural mosaic may not be the most valuable solution if the mean ground cover quality of the corridor mosaic is low. Such configuration should be reserved for conservation plans where connectivity is not the only objective, or when constraints impose conservationists to mobilise the agricultural mosaic. In other contexts, however, stakeholders may have to maintain a suitable ground cover quality over the corridor mosaic. In such situations, we predict that integrating a mosaic of suitable patches does not decrease nor increase the connectivity over a simple good-habitat corridor, and as such, may be a valuable conservation tool. Moreover, connectivity benefits should be weighed against other possible benefits of a mosaic integration. Indeed, monolithic corridors suffer from constitutive problems that prevent more than a few numbers of species with similar requirements to beneficiate from a given corridor. For example, a corridor for a particular species may be a barrier for another one (e.g. Beier and Noss 1998). A heterogeneous corridor composed of a mosaic of ground covers could be more porous to transversal movements, providing a possible trade-off between different species requirements. Moreover, increasing the heterogeneity of a bad quality corridor could decrease the direct and indirect costs of moving into hostile ground covers while maintaining its connectivity benefits. One example of a mosaic corridor has been documented (Eggers et al. 2009) which included mixtures of different vegetation strata, which simultaneously provided connectivity and avoided barrier effect for several beetle species inhabiting woodlands, grasslands and shrublands. The same principle could be applied to a single habitat type, with a mosaic corridor that would include patches of different management regimes: for example, grasslands connected by corridors composed of various mowing regimes.

\section{The role of the agricultural mosaic in the vicinity of the corridor}


Agricultural landscapes are a major playground for the implementation of ecological corridors, at least in human-dominated areas where they support a major proportion of the biodiversity (e.g. $75 \%$ of endangered species on the European continent (Leroux et al. 2008)).

The efficiency of corridors can be affected by the quality of the surrounding matrix (Ricketts 2001). Going further, our results that the structural and compositional heterogeneity of the mosaic surrounding the corridor could be an interesting management target to increase the corridor efficiency, echoing increased focus on the importance of the diversity of ground covers to consider when implementing conservation strategies in agricultural landscapes (Prevedello and Vieira 2010; Fahrig et al. 2010; Driscoll et al. 2013; Vasseur et al. 2013). We observed an increase in functional connectivity with both compositional and structural heterogeneity of the matrix surrounding the corridor. Connectivity gains were mainly due to increases in the success of DFH movements, while pure corridor movements and pure matrix movements were unaffected.

DFH movements were not more frequent (which would have led to a proportional decrease in the frequency of pure corridor movements) but were more likely to reach the target habitat patch. Presumably, a succession of patches of contrasting qualities increased the sinuosity of the paths emigrating from the corridor, eventually redirecting the individuals back into the corridor. An increase in the boundary contrasts (compositional heterogeneity) increased the probability to be reflected by each boundary, while a rise in patches density (structural heterogeneity) increased the likelihood of boundary encounters. Interestingly, pure matrix movements were unaffected, which suggest that only the short foray loops starting from the corridor are affected by the matrix heterogeneity, while long-range matrix movements going directly from one habitat patch to another tend to ignore it (Van Dyck and Baguette 2005). Also, we observed no increase in connectivity with the addition of a narrow mosaic buffer (Fig. $7 \mathrm{~A}, \mathrm{~B}$ ), indicating that the reflection effect of the mosaic surrounding the corridor may need to take place over a large portion of the landscape to be efficient.

A frequent approach to promote corridors in agricultural landscapes is through the conservation or creation of semi-natural linear elements such as grassy field margins (Ockinger and Smith 2008; Van Geert et al. 2010; Delattre et al. 2013) or hedgerows (Burel 1996; Le Coeur et al. 1997; Baudry et al. 2000). In such a scenario, our simulations suggest that a portion of the landscape surrounding the corridor could be included beneficially into an "agricultural buffer". The mosaic of agricultural plots in the buffer would have to be managed to follow specific rules to allow for better functional connectivity, while maintaining their primary agricultural function (Donald and Evans 2006). In the right landscape configuration, the connectivity benefits might be attained by acting on the crop density and inter-crop heterogeneity in the buffer, with a low impact on the farming practices inside the patches, therefore increasing the proportion of landscape mobilisable for 
conservation purposes with lower risks of increasing land-use conflicts.

\section{Acknowledgments}

We warmly thank two reviewers for their helpful comments that helped us to improve the quality of this paper. 


\section{Figure Captions}

Figure 1:

Examples of spatial structures evaluated by the model. Two patches of good habitat (circles) are surrounded by a matrix of more or less favourable habitat (plain grey background orvaried polygons). The matrix might be uniform (be) or composed of a mosaic of patches of various qualities and density $(a, d)$. Habitat patches are connected by a corridor that might be composed of one simple linear stripe $(a, e, f)$, or a linear stripe separated from the matrix by a buffer $(b, c)$. The core linear stripe and the buffer might each be composed of a homogeneous ground cover or a mosaic of patches of various qualities and density.

Fig. 2:

Dispersal success (number of individuals reaching a target patch) ofpure corridor movements (A) and DFH movements $(\boldsymbol{B})$, as a function of the quality of the matrix and that of the corridor. Both corridor and matrix are homogeneous.

Fig. $3(A, B, C)$ :

Effect of different forms of buffered corridors on connectivity from pure corridor movements (B), DFH movements (C) and all paths combined (A). The forms of corridor are: 1) no buffer added(black);2) with a buffer oflesser quality than the core of the corridor (dark grey); 3) with a buffer of better quality than the core of the corridor (light grey); 4) with a buffer of the same quality as the core (i.e. largercore) (white). Matrix quality is set to $Q=10$. Each set of configuration is tested over three different qualities for the core of the corridor $(Q=10, Q=50$ and $Q=90)$.

Fig 4:

Effect of the heterogeneity of a corridor composed of a mosaic of patches of various qualities on the connectivity between habitat patches (number of individuals $\pm S E$, all pathways combined). The compositional heterogeneity corresponds to the standard deviation between the ground cover quality of the patches. Structural heterogeneity corresponds to the patch density. Matrix is homogeneous, with a quality set to $Q=10$.

Fig 5:

Effect of the heterogeneity of a matrix composed of a mosaic of patches of various qualities, on the connectivity between habitat patches (number of individuals $\pm S E$, all pathways combined). The compositional heterogeneity corresponds to the standard deviation between patches habitat quality. Structural heterogeneity corresponds to the patch density. The corridor is homogeneous, with a quality set to $Q=15$.

Fig. 6:

Effect of the heterogeneity of a buffer composed of a mosaic of patches of various qualities (all pathways combined). The compositional heterogeneity is represented by the standard deviation between the ground cover quality of patches. Structural heterogeneity is represented by the patch density. For comparison purposes, a patch density of 0 is shown and corresponds to a homogeneous buffer. The core of the corridor is homogeneous, with a quality set to $Q=15$.

Fig.7:

Dispersal success (number of individuals reaching a target patch), as a function of the best configuration for each corridor form tested in the study. The core of the corridor is composed of a ground cover of bad quality (A) or good quality (B). Dispersal success is represented separately for pure corridor movements (black), DFH movements (grey) and pure matrix movements (white). The corridorforms represented are: 1) a simple corridor composed of a single, homogeneous strip; 2) a buffered corridor composed of a homogeneous core strip ground cover buffered by two contrasted, homogeneous stripes; 3) a corridor consisting of a mosaic of patches of various qualities; 4) a corridor composed of a homogeneous core strip buffered by two stripes composed of a mosaic of patches of various qualities. 


\section{Figures}

\section{Figure 1}
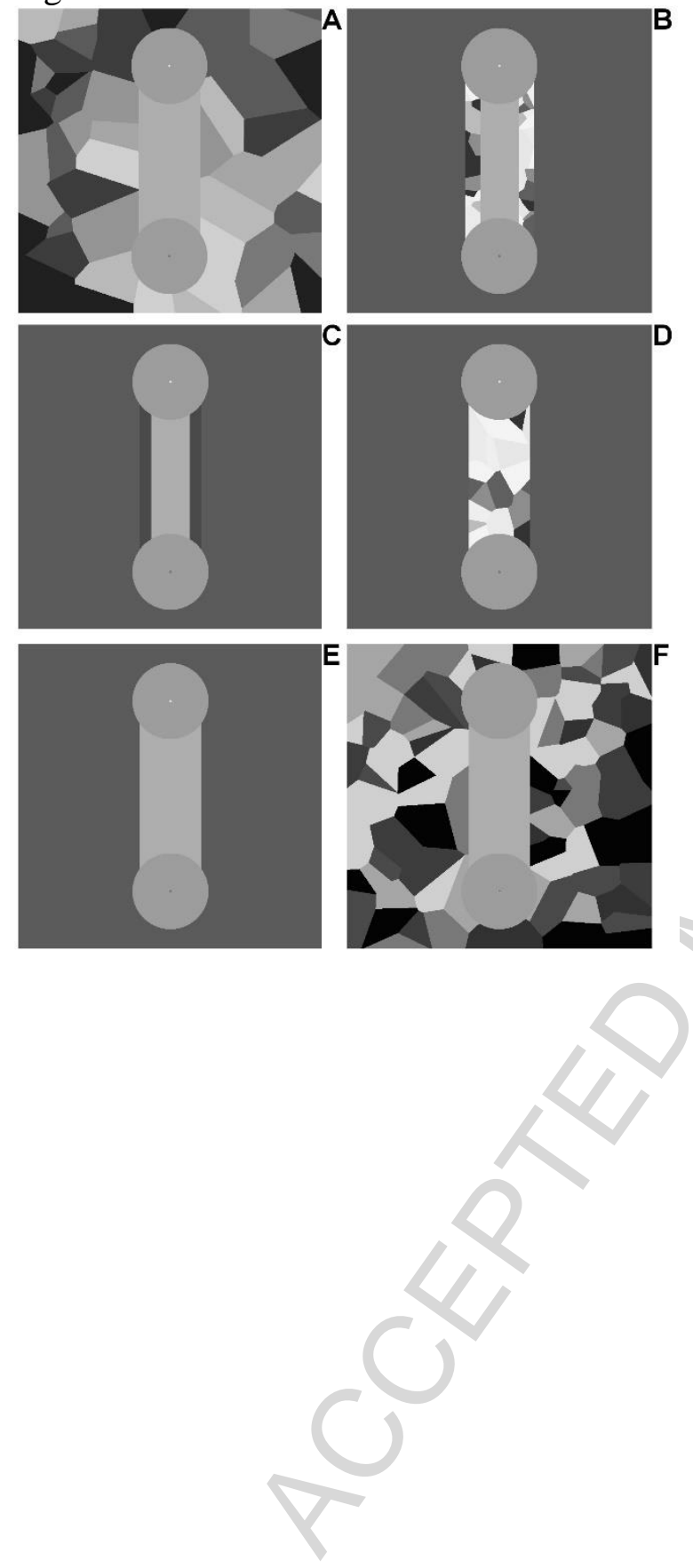
Figure 2
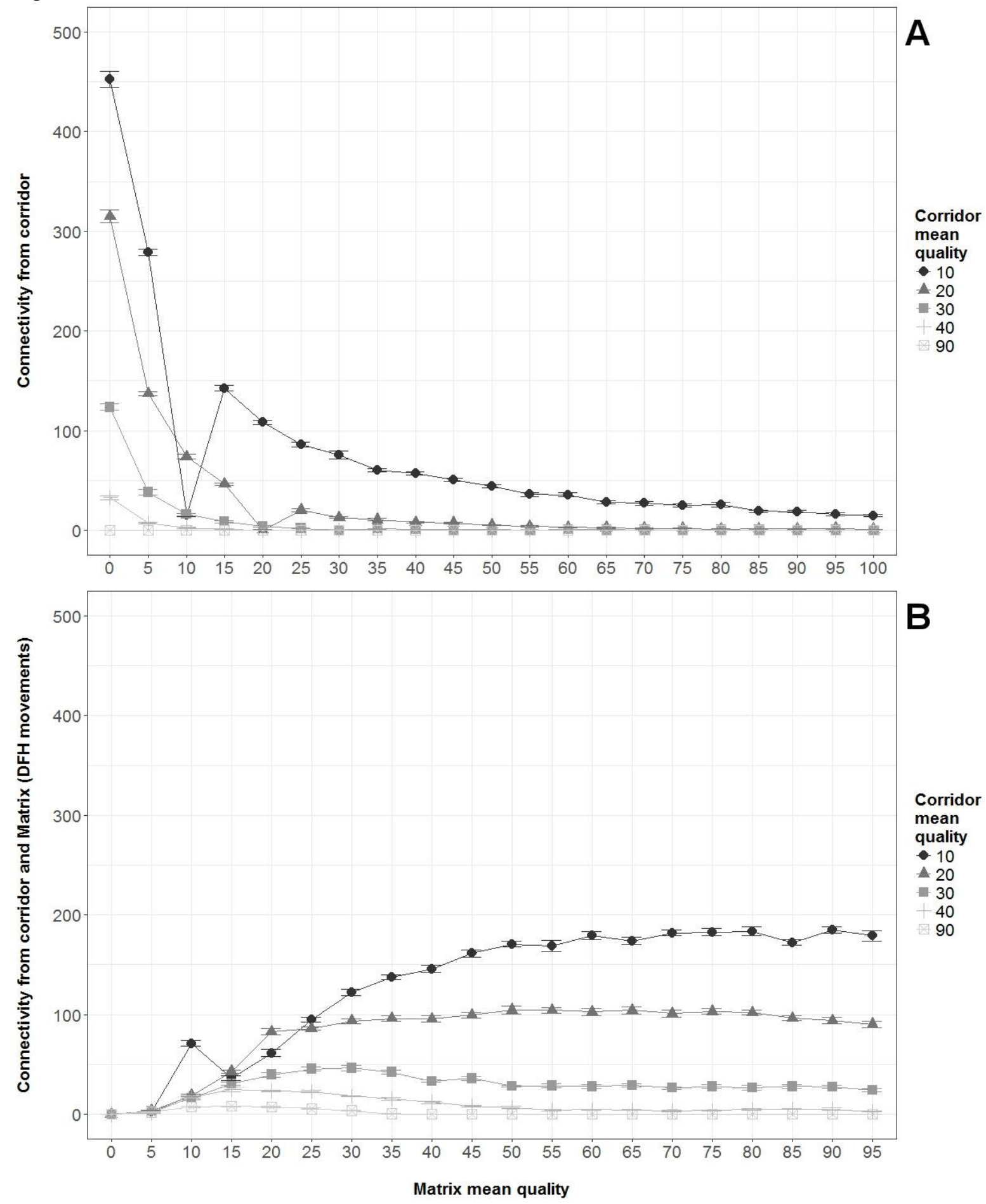

B

Corridor

- 10

-20
-30

$-30$

$+40$

90 
Figure 3

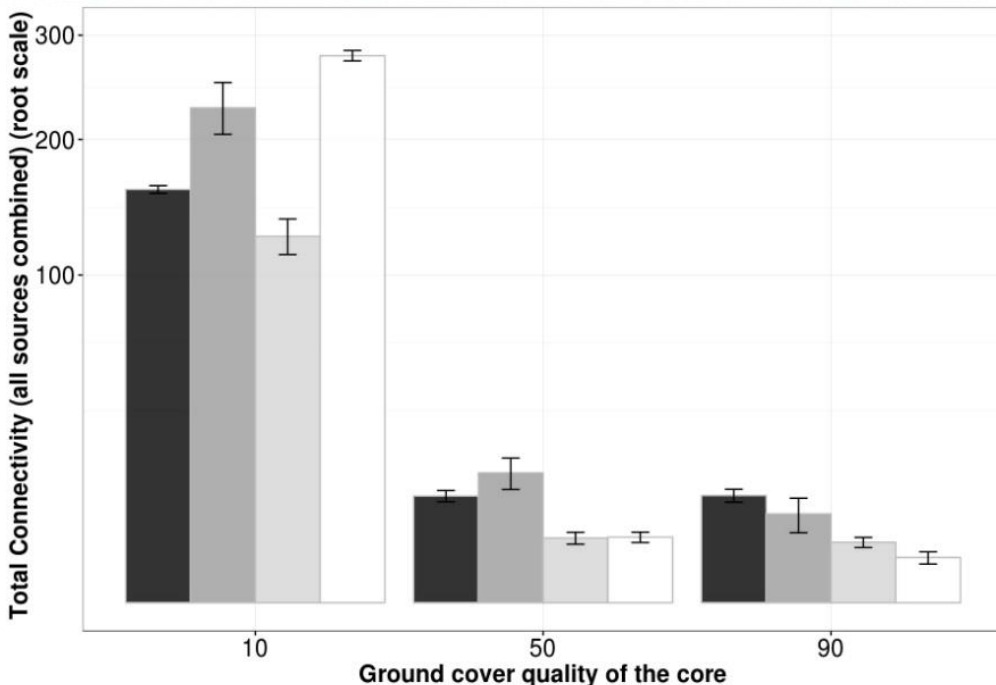

A

\section{Corridor forms}

Without buffer

With buffer (lesser quality)

With buffer (higher quality)

Without buffer (larger core)

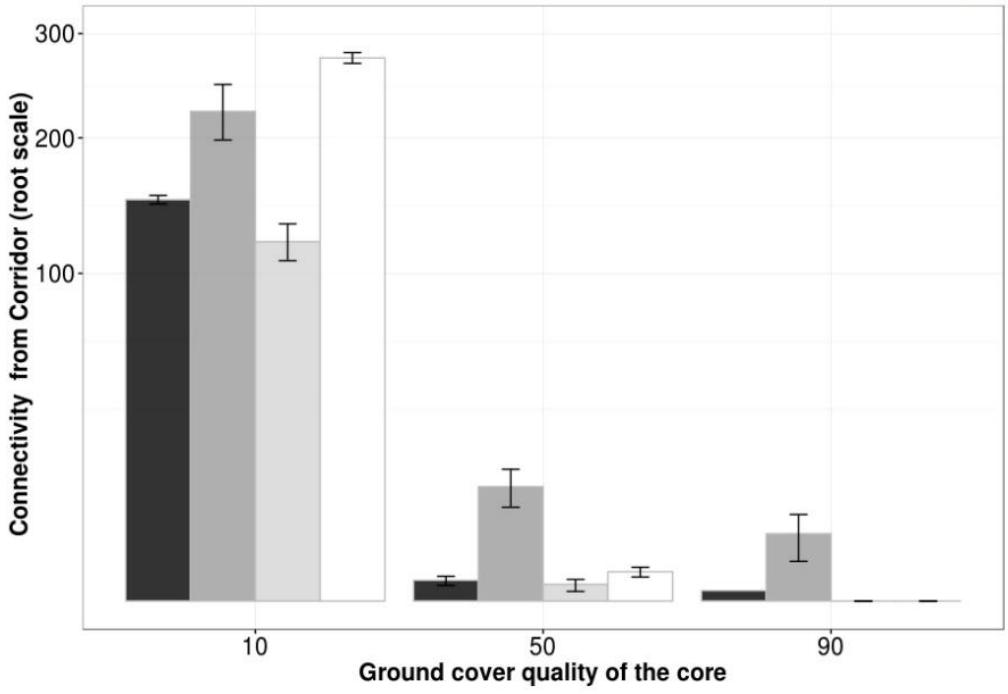

B

\section{Corridor forms}

Without buffer

With buffer (lesser quality)

With buffer (higher quality)

Without buffer (larger core)

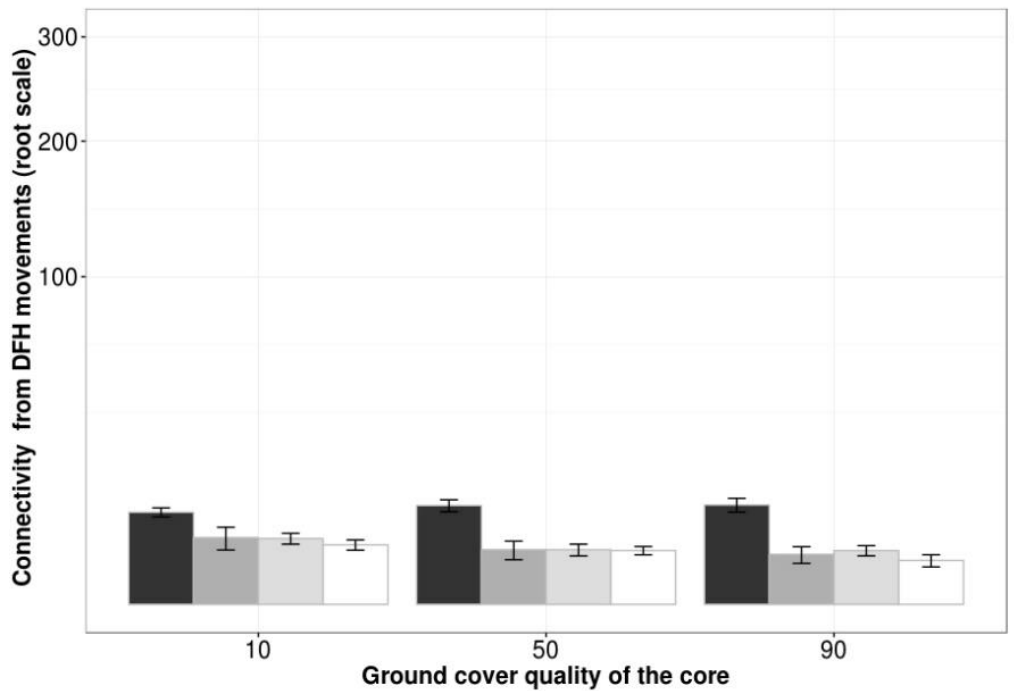

C

Corridor forms

With buffer (lesser quality)

With buter (ligher quality)

Without buffer (larger core) 
Figure 4

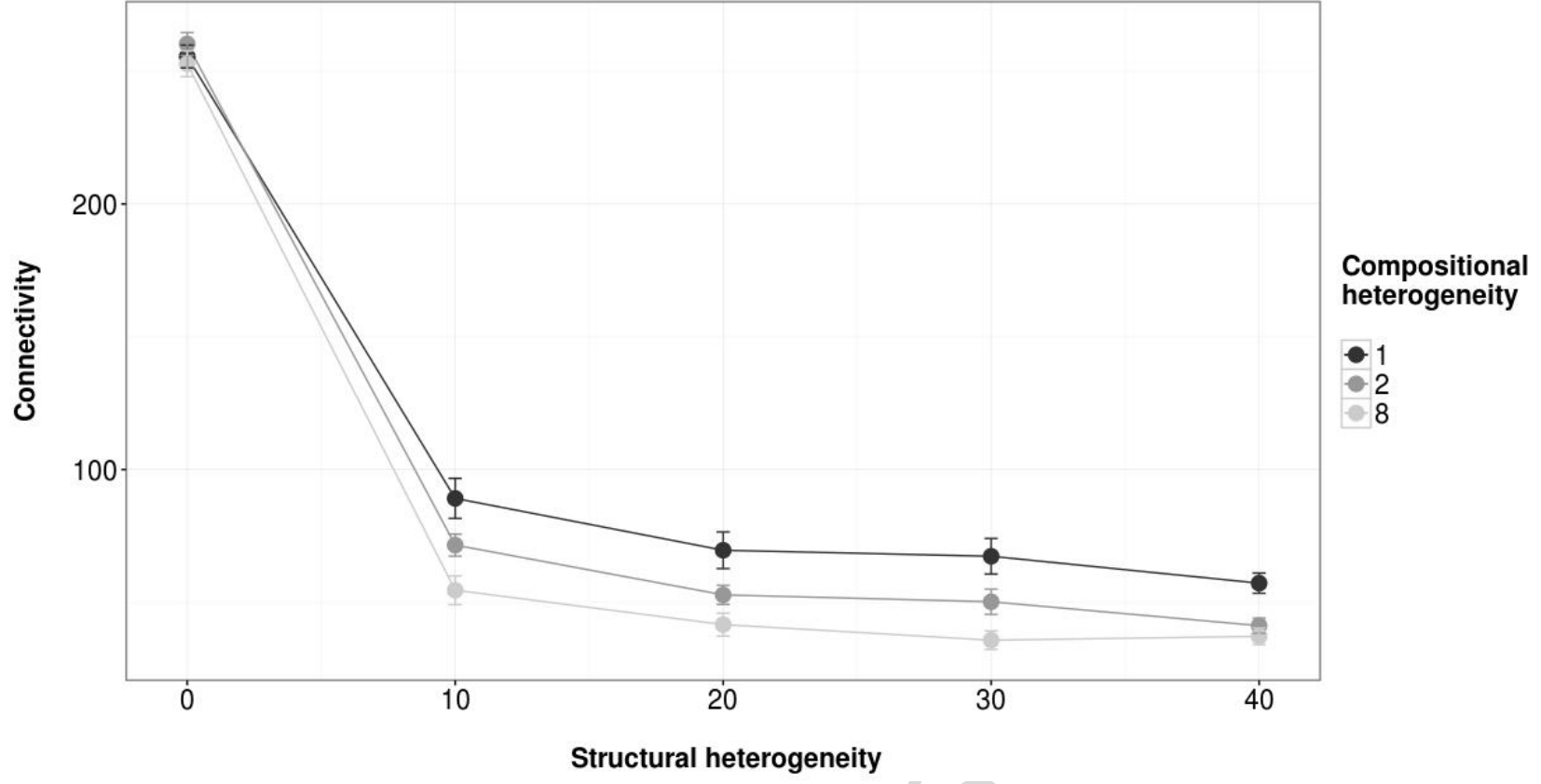


Figure 5

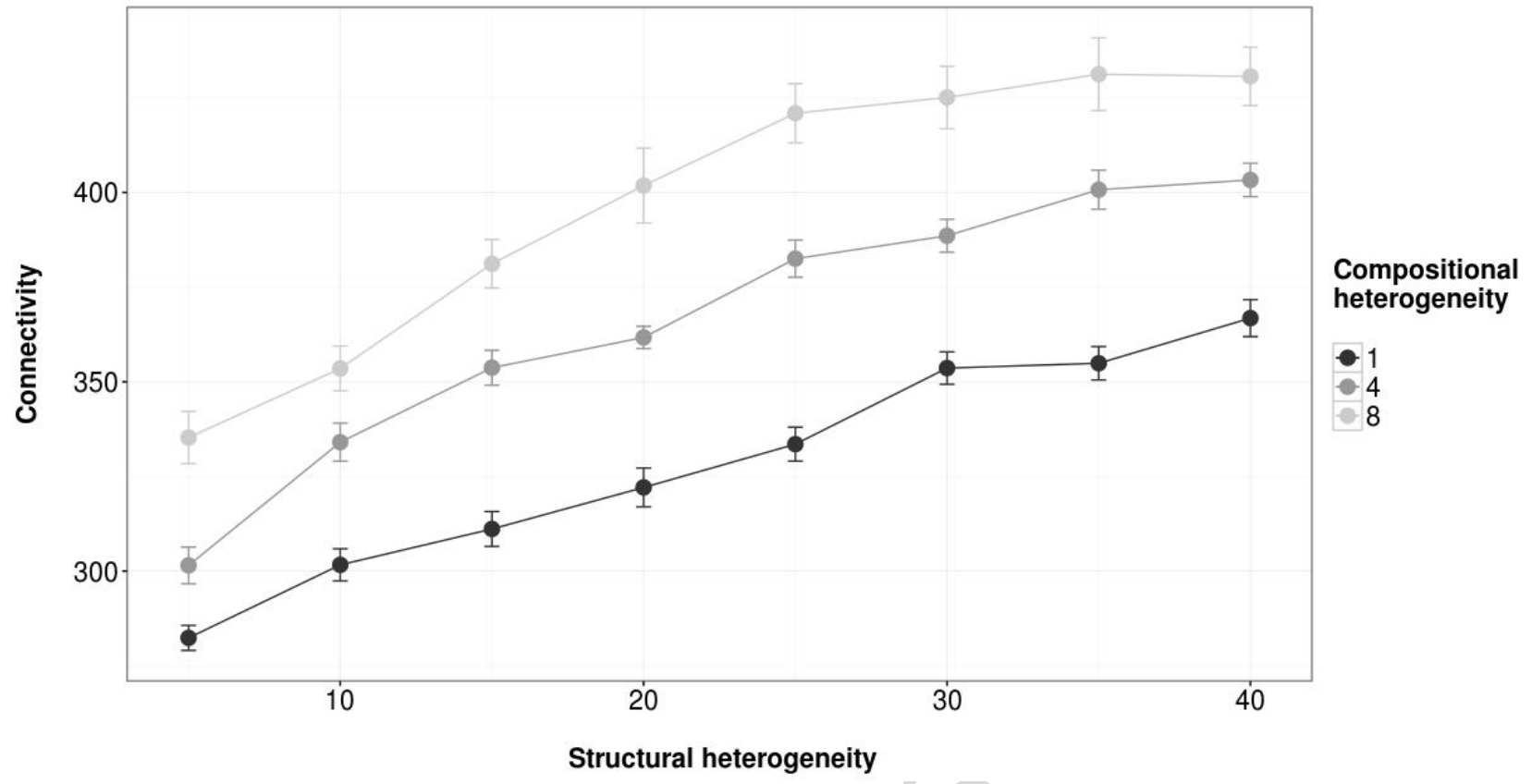


Figure 6

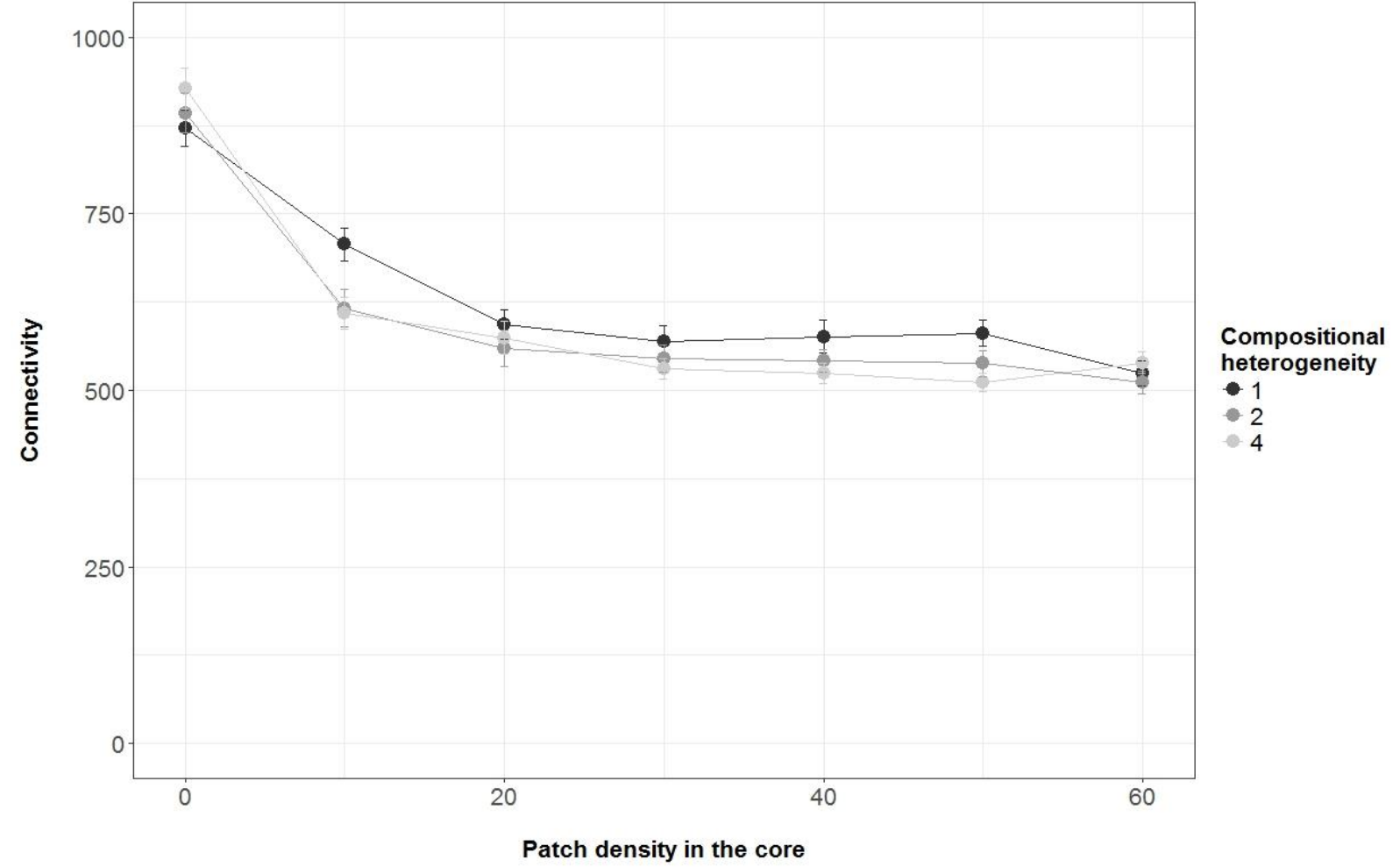


Figure 7
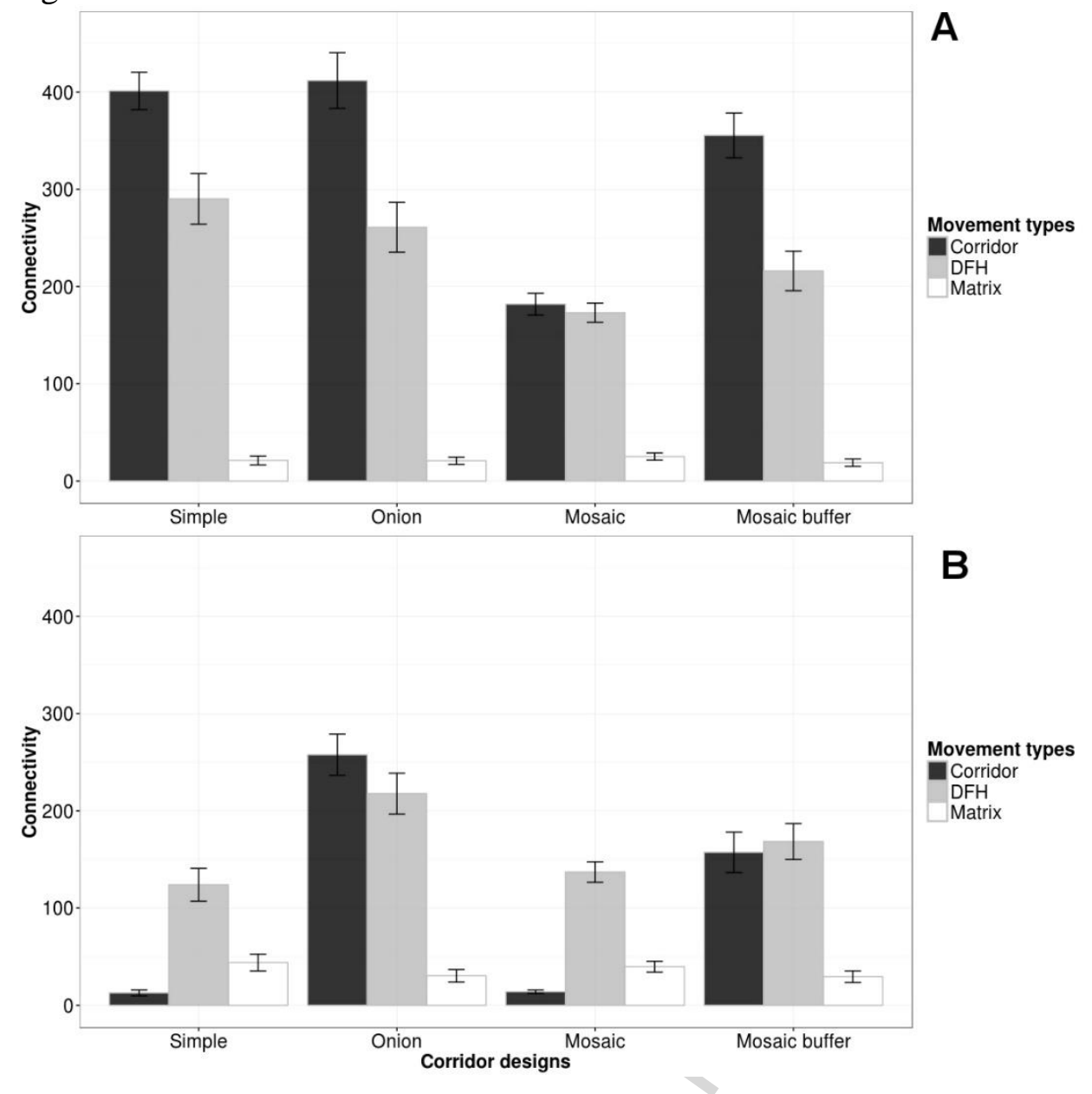


\section{References}

Aurenhammer F (1991) Voronoi diagrams - a survey of a fundamental geometric data structure. ACM Comput Surv 23:345-405.

Baars MA (1979) Patterns of movement of radioactive carabid beetles. 44:125-140. doi: $10.1007 /$ bf00346411

Baguette M (2003) Long distance dispersal and landscape occupancy in a metapopulation of the cranberry fritillary butterfly. Ecography (Cop) 26:153-160.

Baguette M, Blanchet S, Legrand D, et al (2013) Individual dispersal, landscape connectivity and ecological networks. Biol Rev 88:310-326.

Baguette M, Van Dyck H (2007) Landscape connectivity and animal behavior: functional grain as a key determinant for dispersal. Landsc Ecol 22:1117-1129. doi: 10.1007/s10980-007-9108-4

Baudry J, Bunce RGH, Burel F (2000) Hedgerows: an international perspective on their origin, function and management. J Environ Manage 60:7-22.

Beier P, Majka DR, Spencer WD (2008) Forks in the road: choices in procedures for designing wildland linkages. Conserv Biol 22:836-851.

Beier P, Noss RF (1998) Do Habitat Corridors Provide Connectivity? Conserv Biol 12:1241-1252. doi: doi:10.1046/j.1523-1739.1998.98036.x

Belote RT, Dietz MS, McRae BH, et al (2016) Identifying Corridors among Large Protected Areas in the United States. PLoS One 11:e0154223. doi: 10.1371/journal.pone.0154223

Bennett AF (1999) Linkages in the landscape: the role of corridors and connectivity in wildlife conservation. lucn

Boitani L, Falcucci A, Maiorano L, Rondinini C (2007) Ecological networks as conceptual frameworks or operational tools in conservation. Conserv Biol 21:1414-1422.

Bonte D, Van Dyck H, Bullock JM, et al (2012) Costs of dispersal. Biol Rev Camb Philos Soc. doi: 10.1111/j.1469-185X.2011.00201.x

Brook BW, Tonkyn DW, O'Grady JJ, Frankham R (2002) Contribution of inbreeding to extinction risk in threatened species. Conserv Ecol 6:16. 
Brown JH, Kodric-Brown A (1977) Turnover rates in insular biogeography: effect of immigration on extinction. Ecology 58:445-449.

Burel F (1996) Hedgerows and their role in agricultural landscapes. CRC Crit Rev Plant Sci 15:169-190.

Burel F, Baudry J (1995) Social, aesthetic and ecological aspects of hedgerows in rural landscapes as a framework for greenways.

Burel F, Baudry J (1990) Structural dynamic of a hedgerow network landscape in Brittany France. Landsc Ecol 4:197-210.

Burton R, Kuczera C, Schwarz G, others (2008) Exploring Farmers' Cultural Resistance to Voluntary Agri environmental Schemes. Sociol Ruralis 48:16-37.

Ceballos G, Ehrlich PR (2002) Mammal population losses and the extinction crisis. Science (80- ) 296:904907.

Chetkiewicz C-LB, St. Clair CC, Boyce MS (2006a) Corridors for Conservation: Integrating Pattern and Process. Annu Rev Ecol Evol Syst 37:317-342. doi: 10.1146/annurev.ecolsys.37.091305.110050

Chetkiewicz C-LB, St. Clair CC, Boyce MS (2006b) Corridors for Conservation: Integrating Pattern and Process. Annu Rev Ecol Evol Syst 37:317-342. doi: doi:10.1146/annurev.ecolsys.37.091305.110050

Clobert J, Le Galliard JF, Cote J, et al (2009) Informed dispersal, heterogeneity in animal dispersal syndromes and the dynamics of spatially structured populations. Ecol Lett 12:197-209. doi: 10.1111/j.1461-0248.2008.01267.x

Collinge SK, Palmer TM (2002) The influences of patch shape and boundary contrast on insect response to fragmentation in California grasslands. Landsc Ecol 17:647-656.

Conradt L, Roper TJ (2006) Nonrandom Movements Behaviour at Habitat Boundaries in two Butterfly Species : Implications for Dispersal. Ecology 87:125-132.

Coulon A, Aben J, Palmer SCF, et al (2015) A stochastic movement simulator improves estimates of landscape connectivity. Ecology 96:2203-2213.

Crone EE, Schultz CB (2008) Old models explain new observations of butterfly movement at patch edges. Ecology 89:2061-7.

Delattre T, Burel F, Humeau A, et al (2010a) Dispersal mood revealed by shifts from routine to direct flights in the meadow brown butterfly Maniola jurtina. Oikos 119:1900-1908. doi: 10.1111/j.1600- 
0706.2010.18615.x

Delattre T, Pichancourt J-B, Burel F, Kindlmann P (2010b) Grassy field margins as potential corridors for butterflies in agricultural landscapes: A simulation study. Ecol Modell 221:370-377. doi: 10.1016/j.ecolmodel.2009.10.010

Delattre T, Vernon P, Burel F (2013) An Agri-environmental scheme enhances butterfly dispersal in European agricultural landscapes. Agric Ecosyst Environ 166:102-109.

Doerr VA, Barrett T, Doerr ED (2011) Connectivity, dispersal behaviour and conservation under climate change: a response to Hodgson et al. J Appl Ecol 48:143-147.

Donald PF, Evans AD (2006) Habitat connectivity and matrix restoration: the wider implications of agrienvironment schemes. J Appl Ecol 43:209-218. doi: 10.1111/j.1365-2664.2006.01146.x

Dover JW, Fry GLA (2001) Experimental simulation of some visual and physical components of a hedge and the effects on butterfly behaviour in an agricultural landscape. Entomol Exp Appl 100:221-233.

Dover JW, Sparks THT, Greatorex-Davies JNJ (1997) The importance of shelter for butterflies in open landscapes. J Insect Conserv 1:89-97.

Driscoll DA, Banks SC, Barton PS, et al (2013) Conceptual domain of the matrix in fragmented landscapes. Trends Ecol Evol 28:605-613.

Eggers B, Matern A, Drees C, et al (2009) Value of Semi-Open Corridors for Simultaneously Connecting Open and Wooded Habitats: a Case Study with Ground Beetles. Conserv Biol 24:256-266. doi: 10.1111/j.1523-1739.2009.01295.x

Ernoult A, Vialatte A, Butet A, et al (2013) Grassy strips in their landscape context, their role as new habitat for biodiversity. Agric Ecosyst Environ 166:15-27. doi: 10.1016/j.agee.2012.07.004

Fahrig L (2003) Effects of habitat fragmentation on biodiversity. Annu Rev Ecol Evol Syst 34:487-515. doi: 10.1146/annurev.ecolsys.34.011802.132419

Fahrig L, Baudry J, Brotons L, et al (2010) Functional landscape heterogeneity and animal biodiversity in agricultural landscapes. Ecol Lett 14:101-112. doi: 10.1111/j.1461-0248.2010.01559.x

Forman RTT (1983) CORRIDORS IN A LANDSCAPE-THEIR ECOLOGICAL STRUCTURE AND FUNCTION. Ekol Csfr 2:375-387.

Gilbert-Norton L, Wilson R, Stevens JR, Beard KH (2010) A meta-analytic review of corridor effectiveness. 
Conserv Biol 24:660-8. doi: 10.1111/j.1523-1739.2010.01450.x

Gillies CS, St. Clair CC (2008) Riparian corridors enhance movement of a forest specialist bird in fragmented tropical forest. Proc Natl Acad Sci 105:19774-19779. doi: 10.1073/pnas.0803530105

Goodwin BJ, Fahrig L (2002) How does landscape structure influence landscape connectivity? Oikos 99:552-570.

Griffen BD, Drake JM (2008) A review of extinction in experimental populations. J Anim Ecol 77:1274-1287.

Grimm V (1999) Ten years of individual-based modelling in ecology: what have we learned and what could we learn in the future? Ecol Modell 115:129-148.

Grimm V, Berger U, Bastiansen F, et al (2006) A standard protocol for describing individual-based and agent-based models. Ecol Modell 198:115-126. doi: 10.1016/j.ecolmodel.2006.04.023

Grimm V, Berger U, DeAngelis DL, et al (2010) The ODD protocol: A review and first update. Ecol Modell 221:2760-2768. doi: 10.1016/j.ecolmodel.2010.08.019

Grimm V, Railsback SF (2013) Individual-based modeling and ecology. Princeton university press

Haddad NM (1999a) Corridor Use Predicted from Behaviors at Habitat Boundaries. Am Nat 153:215-227. doi: doi: $10.1086 / 303163$

Haddad NM (1999b) Corridor and Distance Effects on Interpatch Movements: a Landscape Experiment With Butterflies. Ecol Appl 9:612-622. doi: 10.1890/1051-0761(1999)009[0612:CADEOI]2.0.CO;2

Haddad NM, Baum K a. (1999) An Experimental Test of Corridor Effects on Butterfly Densities. Ecol Appl 9:623-633. doi: 10.1890/1051-0761(1999)009[0623:AETOCE]2.0.CO;2

Haddad NMM, Tewksbury JJJ (2005) Low-quality habitat corridors as movement conduits for two butterfly species. Ecol Appl 15:250-257.

Hanski I (1999) Metapopulation ecology. Oxford University Press, Oxford

Hanski I (1998) Metapopulation dynamics. Nature 396:41-49.

Haynes K, Cronin J (2006) Interpatch movement and edge effects: the role of behavioral responses to the landscape matrix. Oikos 113:43-54.

Herzele A Van, Wiedemann T (2003) A monitoring tool for the provision of accessible and attractive urban green spaces. 
Hess GR, Fischer RA (2001) Communicating clearly about conservation corridors. Landsc Urban Plan 55:195-208. doi: 10.1016/S0169-2046(01)00155-4

Hodgson JA, Moilanen A, Wintle BA, Thomas CD (2011) Habitat area, quality and connectivity: striking the balance for efficient conservation. J Appl Ecol 48:148-152.

Holmquist JG (1998) Permeability of patch boundaries to benthic invertebrates: influences of boundary contrast, light level, and faunal density and mobility. Oikos 558-566.

Jongman RH, Pungetti G (2004) Ecological networks and greenways: concept, design, implementation. Cambridge University Press

Kanagaraj R, Wiegand T, Kramer-Schadt S, Goyal SP (2013) Using individual-based movement models to assess inter-patch connectivity for large carnivores in fragmented landscapes. Biol Conserv 167:298309. doi: 10.1016/j.biocon.2013.08.030

Kramer-Schadt S, S. Kaiser T, Frank K, Wiegand T (2011) Analyzing the effect of stepping stones on target patch colonisation in structured landscapes for Eurasian lynx. Landsc Ecol 26:501-513. doi: $10.1007 / \mathrm{s} 10980-011-9576-4$

Lawler JJ, Aukema JE, Grant JB, et al (2006) Conservation science: a 20-year report card. Front Ecol Environ 4:473-480.

Le Coeur D, Baudry J, Burel F (1997) Field margins plant assemblages: variation partitioning between local and landscape factors. Landsc Urban Plan 37:57-71.

Leroux X, Barbault R, Baudry J, et al (2008) Agriculture et biodiversité: valoriser les synergies.

Lima SL, Zollner PA (1996) Towards a behavioral ecology of ecological landscapes. Trends Ecol Evol $11: 131-135$.

McIntire E, Rompré G, Severns P (2013) Biased correlated random walk and foray loop: which movement hypothesis drives a butterfly metapopulation?

Ockinger E, Smith HG (2008) Do corridors promote dispersal in grassland butterflies and other insects? Landsc Ecol 23:27-40. doi: 10.1007/s10980-007-9167-6

Oliver T, Hill JK, Thomas CD, et al (2009) Changes in habitat specificity of species at their climatic range boundaries. Ecol Lett 12:1091-1102.

Pereira HM, Leadley PW, Proença V, et al (2010) Scenarios for global biodiversity in the 21st century. 
Science (80- ) 330:1496-1501.

Prevedello JA, Vieira MV (2010) Does the type of matrix matter? A quantitative review of the evidence.

Biodivers Conserv 19:1205-1223.

R Development Core Team (2009) R: A language and environment for statistical computing.

Ricketts TH (2001) The matrix matters: effective isolation in fragmented landscapes. Am Nat 158:87-99.

Rodriguez A, Delibes M (2003) Population fragmentation and extinction in the lberian lynx. Biol Conserv 109:321-331.

Saunders DADA, Hobbs RJRJ, Margules CR (1991) Biological Consequences of Ecosystem Fragmentation: A Review. Conserv Biol 5:18-32.

Savard J-PL, Clergeau P, Mennechez G (2000) Biodiversity concepts and urban ecosystems. Landsc Urban Plan 48:131-142. doi: 10.1016/S0169-2046(00)00037-2

Schlaepfer MA, Runge MC, Sherman PW (2002) Ecological and evolutionary traps. Trends Ecol Evol $17: 474-480$.

Schtickzelle N, Joiris A, Van Dyck H, Baguette M (2007a) Quantitative analysis of changes in movement behaviour within and outside habitat in a specialist butterfly. BMC Evol Biol 7:15. doi: 410.1186/14712148-7-4

Schtickzelle N, Turlure C, Baguette M (2007b) Grazing management impacts on the viability of the threatened bog fritillary butterfly Proclossiana eunomia. Biol Conserv 136:651-660. doi: 10.1016/j.biocon.2007.01.012

Schultz CB (1998) Dispersal Behavior and Its Implications for Reserve Design in a Rare Oregon Butterfly. Conserv Biol 12:284-292. doi: doi:10.1046/j.1523-1739.1998.96266.x

Simberloff D, Farr JAJA, Cox J, Mehlman DWDW (1992) Movement Corridors: Conservation Bargains or Poor Investments? Conserv Biol 6:493-504. doi: 10.1046/j.1523-1739.1992.06040493.x

Soulé ME, Gilpin ME (1991) The theory of wildlife corridor capability. In: Saunders DA, Hobbs RJ (eds). Surrey Beatty, Chipping Norton,

Stevens VM, Baguette M (2008) Importance of Habitat Quality and Landscape Connectivity for the Persistence of Endangered Natterjack Toads. Conserv Biol 22:1194-1204. doi: 10.1111/j.15231739.2008.00990-x 
Taylor PD, Fahrig L, Henein K, Merriam G (1993) Connectivity Is a Vital Element of Landscape Structure. Oikos 68:571-573.

Theobald DM, Reed SE, Fields K, Soulé M (2012) Connecting natural landscapes using a landscape permeability model to prioritize conservation activities in the United States. Conserv Lett 5:123-133. doi: 10.1111/j.1755-263X.2011.00218.x

Tilman D, Lehman CL, Yin C (1997) Habitat destruction, dispersal, and deterministic extinction in competitive communities. Am Nat 407-435.

Tischendorf L, Wissel C (1997) Corridors as conduits for small animals : attainable distances depending on movement pattern, boundary reaction and corridor width. Oikos 79:603-611.

Tisue S, Wilensky U (2004) Netlogo: A simple environment for modeling complexity. Boston, MA, pp 16-21

Tscharntke T, Steffan-Dewenter I, Kruess A, Thies C (2002) Contribution of small habitat fragments to conservation of insect communities of grassland-cropland landscapes. Ecol Appl 12:354-363.

Van Dyck H, Baguette M (2005) Dispersal behaviour in fragmented landscapes: Routine or special movements? Basic Appl Ecol 6:535-545. doi: 10.1016/j.baae.2005.03.005

Van Geert A, Van Rossum F, Triest L (2010) Do linear landscape elements in farmland act as biological corridors for pollen dispersal? J Ecol 98:178-187. doi: 10.1111/j.1365-2745.2009.01600.x

Vasseur C, Joannon A, Aviron S, et al (2013) The cropping systems mosaic: How does the hidden heterogeneity of agricultural landscapes drive arthropod populations? Agric Ecosyst Environ 166:3-14.

Viljur M-L, Teder T (2018) Disperse or die: Colonisation of transient open habitats in production forests is only weakly dispersal-limited in butterflies. Biol Conserv 218:32-40. doi: 10.1016/j.biocon.2017.12.006

Vitousek PM, Mooney HA, Lubchenco J, Melillo JM (1997) Human domination of Earth's ecosystems. Science (80- ) 277:494-499.

Vos CC, Baveco H, Grashof-Bokdam CJ (2002) Corridors and Species Dispersal. In: Applying Landscape Ecology in Biological Conservation. Springer New York, New York, NY, pp 84-104

Zollner PA, Lima SL (1999) Search strategies for landscape-level interpatch movements. Ecology 80:10191030. 
An onion-like movement corridor? Possible guidelines emerging from small-scale movement rules.

Thomas Delattre ${ }^{(1, *)}$, Jacques Baudry ${ }^{(2)} \&$ Françoise Burel $^{(3)}$

\section{Highlights:}

- We evaluated the connectivity benefits brought by unconventional corridor designs.

- Unfavourable ground covers may increase the efficiency of movement corridors.

- An "onion corridor" composed by several layers of habitats could favour connectivity.

- The heterogeneity of a mosaic corridor decreases movement rates. 